\title{
Flora do Rio de Janeiro: Cabombaceae
}

\author{
Flora of Rio de Janeiro: Cabombaceae
}

\author{
Aline de Jesus Correia ${ }^{1}$ \& Claudia Petean Bove $e^{1,2}$
}

\begin{abstract}
Resumo
O presente estudo tem como objetivo contribuir para o conhecimento das espécies de Cabombaceae ocorrentes no estado do Rio de Janeiro. O trabalho tem por base a análise morfológica de materiais depositados em herbários e coletas de campo, além da compilação de dados de literatura. Foram registrados um gênero e duas espécies: Cabomba caroliniana e Cabomba furcata. Chave para identificação, descrições, dados sobre hábitat, fenologia e distribuição geográfica das espécies são apresentados.
\end{abstract}

Palavras-chave: Cabomba, florística, planta aquática, taxonomia.

\begin{abstract}
This study focuses on the Cabombaceae found in the state of Rio de Janeiro. It is based on a morphological analysis of herbaria collections, as well as on a review of the relevant literature and on collections in the field. A total of one genera and two species were recorded for the state: Cabomba caroliniana and Cabomba furcata. An identification key, descriptions, habitat data, phenology, and species distribution are also provided.

Key words: Cabomba, floristic inventories, aquatic plant, taxonomy.
\end{abstract}

Cabombaceae Rich. ex A. Rich.

Ervas aquáticas perenes, raro anuais, submersas a flutuantes. Rizoma alongado ou pouco desenvolvido, ancorado ao substrato, caules alongados. Folhas mono ou dimórficas, pecioladas, alternas, opostas ou verticiladas, as flutuantes peltadas, estreitamente elípticas a amplamente ovais; as submersas dissectas. Flores emergentes, solitárias, bissexuadas, actinomorfas, hipóginas, 2-3-meras, pedicelos longos; estames 3-36, livres, filetes achatados, anteras oblongas, basifixas, 2-tecas, extrorsas com deiscência longitudinal; carpelos (1-)2-18, livres, estilete terminal ou decurrente, óvulos (1-)2-5, placentação laminar. Fruto coriáceo, indeiscente; sementes 1-3, globosas a ovoides, embrião diminuto, endosperma escasso, perisperma abundante.

Família praticamente cosmopolita, constituída pelo gênero monotípico Brasenia Schreb. e Cabomba Aubl. No Brasil ocorre somente o gênero Cabomba, em ambientes lênticos (lagoas e remanso de rios). Muito cultivadas para comercialização no mercado de aquários.

1. Cabomba Aubl. Hist. Pl. Guiane 1: 321, pl. 124 Caule cilíndrico ou achatado, 2-4 mm diâm. Folhas submersas opostas cruzadas ou verticiladas, geralmente 3-4 folhas por nó, lâmina multipartida, reniforme a quase circular no contorno, 3-5-partida na base, com segmentos lineares fendidos ditricotomicamente; as flutuantes alternas, peltadas, lâmina inteira, amplamente elíptica a oval ou oblonga a sagitada. Flores emersas, nas axilas das folhas flutuantes; sépalas 2-3, oblongas, brancas, amarelas, lilases a róseas; pétalas $2-3$, unguiculadas, ovadas, base auriculada, ápice obtuso, brancas, amarelas, lilases a róseas, nectários 2 , inseridos nas aurículas; estames 3-6, anteras amarelas; gineceu dialicarpelar, carpelos 1-4, ovários uniloculares, óvulos 1-5 por lóculo, estilete delgado, estigma terminal capitado. Fruto ovoide a elipsoide com ápice alongado.

\footnotetext{
${ }^{1}$ Universidade Federal do Rio de Janeiro, Depto. Botânica, Museu Nacional, São Cristóvão, 20940-040, Rio de Janeiro, RJ, Brasil.

${ }^{2}$ Autor para correspondência: cpbove@hotmail.com
} 
Gênero com cinco espécies que ocorrem desde o leste dos Estados Unidos até o norte da Argentina. No Brasil são encontradas três espécies e duas variedades: Cabomba aquatica, C. caroliniana var. flavida e var. caroliniana e C. furcata. Apesar de BFG (2015) citar $C$. aquatica como ocorrente para o estado do Rio de Janeiro, não há registro desta espécie nos herbários do estado, nem na plataforma do species Link ( $<$ http://www.splink.org. $\mathrm{br} />$ ). Intensos esforços de coleta nos últimos vinte anos não detectaram sua ocorrência. Família é representada no estado somente por C. caroliniana var. caroliniana e C. furcata tanto em ambiente de restinga como pode ser encontrada cultivada em pequenas lagoas.

\section{Chave para identificação das espécies de Cabomba}

1. Folhas submersas geralmente opostas, raro em verticilos de 3 , as flutuantes verdes a verde-olivas, sem margem púrpura; flores alvas ou amarelo-claras 1.1. Cabomba caroliniana

1'. Folhas submersas em verticilos de 3, as apicais frequentemente opostas, as flutuantes verde-olivas, margem púrpura; flores lilases 1.2. Cabomba furcata

1.1. Cabomba caroliniana A. Gray. Ann. Lyceum Nat. Hist. New York 4: 46-47.

Folhas submersas opostas, raramente verticiladas, pecíolo ca. $1,5 \mathrm{~cm}$ compr., lâmina foliar com divisões terminais lineares ou brevemente espatuladas, dispostas em um plano, ca. $3 \mathrm{~cm}$ diâm.; folhas flutuantes, lâmina ca. 2 cm compr., estreitamente elípticas a sagitadas, pecíolo ca. 2,5 $\mathrm{cm}$ compr., verdes a verde-olivas. Flores $9-10 \mathrm{~mm}$ compr., pedicelo ca. $4 \mathrm{~cm}$ compr.; perianto alvo ou amarelo-claro; sépalas $9 \times 3 \mathrm{~mm}$, oblongas; pétalas oblongas a obovais, base fortemente auriculada; estames (3-)6, carpelos (2-)3, óvulos $1-3$. Sementes ovais a elipsoides, verrucosas (Orgaard 1991).

Material examinado: Magé, Lagoa Azul, 22.I.1982, fl., Zila Andrade (GUA 21921); Ponta Grossa dos Fidalgos, Lagoa Feia, 11.VIII.1978, fl., D.S. Araujo et al. 2125 (GUA); Rio de Janeiro, Floresta da Tijuca, Açude da Solidão, 24.XII.1975, fl., D. Araujo 931 \& M.C. Viana 621 (GUA)

No Brasil é encontrada nas regiões CentroOeste, Sul e Sudeste. No Rio de Janeiro ocorre em lagoas na restinga e em floresta ombrófila, nos quadrantes: K33, R18, T15. Apenas a variedade $C$. caroliniana var. caroliniana, facilmente distinta pelas flores brancas (em vez de amarelas), é encontrada no Estado. Coletada com flores nos meses de janeiro, agosto e dezembro. Espécie amplamente ilustrada (e.g., Caspary 1878; Orgaard 1991; Vialette-Guiraud et al. 2011).

1.2. Cabomba furcata Schult. \& Schult. f. Syst. Veg. 7(2): 1379.

Folhas submersas em verticilos de 3 , as apicais frequentemente opostas, pecíolo ca. $1,7 \mathrm{~cm}$ de compr., lâmina foliar com divisões terminais lineares dispostas em um plano, ca. $3 \times 3,5 \mathrm{~cm}$ diâm.; folhas flutuantes ca. $1,5 \mathrm{~cm}$ compr., lineares a ocasionalmente sagitadas, verde-olivas, margem púrpura, pecíolo ca. $4 \mathrm{~cm}$ compr. Flores $7-10 \mathrm{~mm}$ compr., pedicelo ca. 3,5 cm compr.; sépalas $9 \times$ $3 \mathrm{~mm}$, obovais a elípticas, base amarela, ápice púrpura; pétalas $8 \times 3 \mathrm{~mm}$, ovais a oblongas, ligeiramente auriculadas, base amarela, ápice púrpura; estames (5-)6, carpelos (1-)3, óvulos (1-)5 alguns frequentemente abortados. Fruto ovoide a elipsoide ca. 3-4 $42 \mathrm{~mm}$, com pequeno espinho apical de ca.1-2 mm; sementes globosas. Material selecionado: Campos dos Goytacazes, Ponta Grossa dos Fidalgos, Lagoa Feia, 11.XII.2004, fl., C.P. Bove et al. 1423 (R); Nova Iguaçu, Vila de Cava, 24.X.2000, fl., W. Costa (R 212045); Silva Jardim, Lagoa de Juturnaíba, Álcalis, X.1986, fl., M. Zeppin 2 (GUA); Poço d'Anta, 14.IX.1977, fl. e fr., J.P.P. Carauta et al. 2675 (GUA, RB); Resende, Porto Real, Rio Paraíba do Sul, 22.X.1981, fl., J.P.P. Carauta et al. 3872 (GUA); Rio de Janeiro, Alto da Boa Vista, Estrada da Vista Chinesa, Km 2, 20.III.1981, fl. e fr., A. G. Carvalho 1 (GUA).

No Brasil é encontrada nas regiões Norte, Nordeste, Centro-Oeste e Sudeste. No Rio de Janeiro ocorre em lagoas na restinga, lagoas e remanso de rios em floresta estacional e ombrófila, nos quadrantes: K33, N31, P6, P24, Q23, R14, R24, T15. Coletada com flores nos meses de março, abril, junho, setembro, outubro, novembro e dezembro e com fruto nos meses de março e setembro. É utilizada como abrigo e alimento para pequenos peixes e invertebrados; também como planta medicinal e ornamental (Pott \& Pott 2000). Espécie amplamente ilustrada (e.g., Caspary 1878; Feres \& Amaral 2003; Orgaard 1991). 


\section{Agradecimentos}

Aos curadores e equipe dos herbários R, RB, RFA, GUA. À Universidade Federal do Rio de Janeiro, a bolsa PIBIC/UFRJ para primeiro autor. E ao CNPq (edital PROTAX 562251/2010-3), a bolsa de produtividade para C.P. Bove.

\section{Referências}

BFG 2015. Growing knowledge: an overview of seed plant diversity in Brazil. Rodriguésia 66: 1085-1113.

Caspary, J.X.R. 1878. Nymphaeaceae. In: Martius, C.F.P.; Eichler, A.W. \& Urban, I. (eds.). Flora Brasiliensis. Typographia Regia. Fr. Fleicher, Liepizig. Vol. 4, pars 2, pp. 129-184, t.37-38.

Fasset, N.C. 1953. Monograph of Cabomba. Southern Appalachian Botanical Society. Castanea 18: 116128.

Feres, F. \& Amaral, M.C.E. Cabombaceae. 2003. In: Wanderley, M.G.L.; Shepherd, G.J.; Melhem, T.S.; Giulietti, A.G. \& Kirizawa, M. (org.). Flora Fanerogâmica do estado de São Paulo. Instituto de Botânica, São Paulo. Vol. 3, pp. 9-11.
Francisco, L.V. \& Barreto, R.C. 2007. Cabomba Aubl. Cabombaceae: caracterização morfoecológica e delimitação entre as espécies ocorrentes no Brasil. Revista Brasileira de Biociências 5: 1077-1079.

Lima, C.T.; Giulietti, A.M. \& Santos, F.A.R. 2012. Flora da Bahia: Cabombaceae. Sitientibus série Ciências Biológicas 12: 61-68.

Orgaard, M. 1991. The genus Cabomba (Cabombaceae) - a taxonomic study. Nordic Journal of Botany 11: 179-203.

Pott, V.J. \& Pott, A. 2000. Plantas aquáticas do Pantanal. Centro de Pesquisas Agropecuária do Pantanal. Embrapa comunicação para transferência de tecnologia, Brasília. 404p.

Vialette-Guiraud, A.C.M.; Alaux, M.; Legeai, F. \& Finet, C. et al. 2011. Cabomba as a model for studies of early angiosperm evolution. Annals of Botany 108: 589-598.

Williamson, P.S. \& Schneider, E.L. 1993. Cabombaceae. In: Kubitzki, K.; Rohwer, J.G. \& Bittrich, V. (eds.). The families and genera of vascular plants. Vol. 2. Springer Verlag, Berlin. Pp. 157-161.

\section{Lista de exsicatas}

Andrade, Z. s.n. (GUA 21921) (1.1); Araujo, D.S. 931 (1.1), 3042 (1.2), 1340 (1.2), 2125 (1.1); Bove, C.P. 1423 (1.2); Carauta, J.P.P. 2675 (1.2), 3872 (1.2); Casari, M.B. 472 (1.2), 631 (1.2), 740 (1.2); Carvalho, A.G. 1 (1.2); Costa, W. s.n. (R 212045) (1.2); Galvão, R. 665 (1.2); Kuhlman, J.G. s.n. (RB 4279)(1.2); Oliveira, R.F. s.n. (GUA 13071) (1.2); Passarelli, A. 107 (1.2); Zeppin, M. 2 (1.2), 57 (1.2), s.n. (GUA 30308) (1.2). 